\title{
La realeza persa y su estructuración administrativa en la «historia» de Heródoto. Una confrontación entre Oriente y Occidente
}

\author{
José Antonio Rodríguez VALCÁRCEL
}

Heródoto participa a lo largo de toda su obra de una serie de oposiciones patentes entre el mundo persa y el mundo griego. Una de ellas, que tendrá posteriormente una gran importancia, será la de la monarquía y la figura del rey como cabeza de una organización y una estructuración de la sociedad que se opondrá al «modo griego».

Los griegos intentaron comprender el imperio persa y definir así la tiranía como algo opuesto a la monarquía ${ }^{1}$, con la voluntad de imitarlo posteriormente. Muchos conceptos esenciales encontrarán un lugar incluso en el mundo judeo-cristiano, como el universalismo y el idealismo del imperio, nacidos ambos del zoroastrismo, pudiendo ser considerados como más civilizadores que las ambiciones de la Atenas de Pericles. Por otro lado, mucho de lo que sabemos de los Aqueménidas proviene de sus tradicionales enemigos. No obstante, Persia tenía muchos admiradores entre los griegos y a despecho de la tiranía y la crueldad contaba con muchas pruebas de la grandeza de carácter que constituía un factor básico en el desarrollo del imperio ${ }^{2}$. El imperio Aqueménida duró más de dos siglos, únicamente el despotismo podía haberle asegurado una existencia tan larga, tanto como la existencia de su encarnación: el palacio real. La arquitectura estará fundada enteramente en la exaltación y el culto de la persona real. Será un arte nacido de la voluntad monárquica que busca unir, en unas concepciones grandiosas, los elementos hetero-

1 PLÁCIDo, D.: «La teoría de la realeza y las realidades históricas del siglo Iv a.C.» en $L a$ imagen de la realeza en la Antigüedad, Madrid, 1988, pág. 35.

2 CULICAN, W.: Medos e persas, Lisboa, 1971. 
géneos, constituyentes de las civilizaciones de los países sometidos ${ }^{3}$ (figuras 1 y 2)

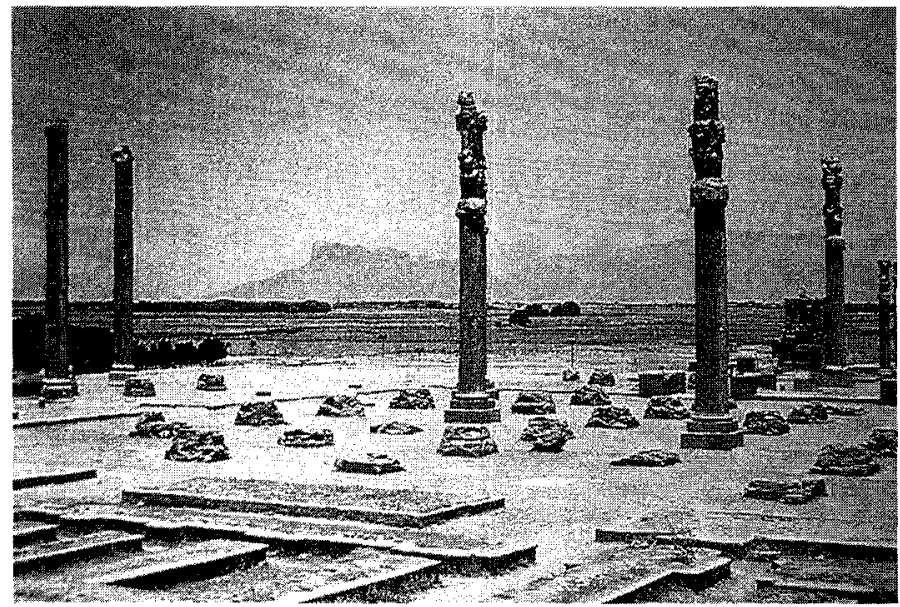

Figura 1. Apadana o Sala de Audiencias del palacio de Persépolis. Levantada por Darío y Jerjes entre los años 515 y 458, estaba destinada a las ceremonias oficiales.

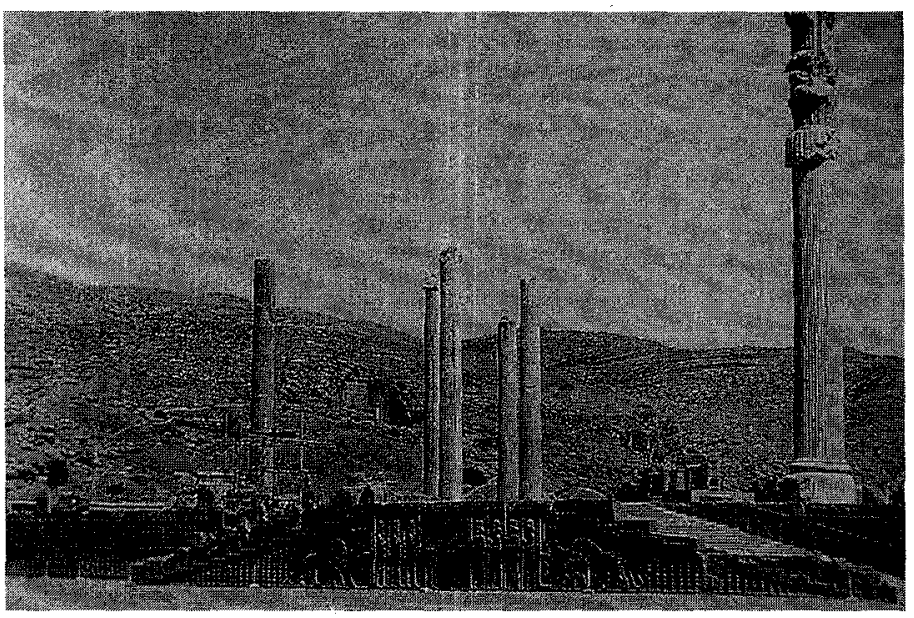

Figura 2. Escalinata de acceso a la Apdana. Sus relieves muestran la procesión de rendición de tributos de las satrapías, así como la guardia real de los "Inmortales».

3 Huot, J.L.: Iran: Des origines aux Achemenides, I, Geneve, 1965, págs. 156-157. 
Políticamente, la concepción persa del poder y de la relación del «Gran Rey» con sus súbditos era irreconciliable con la idea occidental y griega de libertad. Para el "Gran Rey» todos sus súbditos, cualquiera que fuera su condición u origen, eran, en última instancia, esclavos.

A mediados del siglo v, el recuerdo de las Guerras Médicas estaba aún muy presente en las mentes de los griegos. La victoria sobre Persia no era otra cosa que la gran epopeya del pueblo de Atenas y, cantada por Heródoto, su intencionalidad política se hacía evidente. Dicho enfrentamiento había sido inevitable, pues diversas rivalidades entre ambos pueblos estaban confluyendo en ese momento, marcadas por diferencias políticas e institucionales: el universalismo bárbaro con su constante expansión y el mundo griego dividido y múltiple, con una necesidad de expansión mercantil.

A pesar de las diferencias, lo que llama a Heródoto la atención es la organización administrativa persa, donde todo emana del rey y revierte a él, por ello cae en una cierta ambigüedad al admirar su sistema organizativo - lo cual le valió críticas como la de Plutarco-, aunque frente a la crueldad despótica persa, alabe, por supuesto, el régimen griego. Este hecho hará que iniciemos nuestra descripción hablando sobre el origen de la realeza persa.

\section{EL ORIGEN DE LA REALEZA PERSA AQUEMÉNIDA}

Los reinos existentes antes del tercer milenio duraron en Mesopotamia hasta la conquista del imperio neobabilónico por Ciro y los persas en el 539 a.C. Ciro no destruirá nada y se contentará con tomar el título de «rey de Babilonia, rey de los países» ${ }^{4}$. Según Dumezil ${ }^{5}$, la sociedad persa se distribuía en tres órdenes sociales, de los cuales el primero es el que se distinguía por la función de la soberanía que concierne a la administración mágica y jurídica del mundo, del pensamiento y de la sociedad. Al comienzo del «Libro de los Reyes», el rey Djamshid repartirá a los hombres en cuatro clases, haciendo uso de las facultades conferidas como rey ${ }^{6:}$ 1) ASRAVAN, los dedicados al culto; 2) ARTESHTAR, los guerreros y pro-

\footnotetext{
4 Mousnier, R.: Monarchies et royautés, París, 1989, pág. 158; OLMSTEAD, A.T. History of the persian empire, Chicago, 1978, pág. 51.

5 DumEZIL, G.: «Les classes sociales dans la Perse ancienne», pp. 37-41 en La civilisation iranienne, París, 1952.

6 DUMEZIL, G.: op. cit., n. ${ }^{\circ} 16$.
} 
tectores del trono real; 3) VASTRIOSH, los trabajadores que plantan y recolectan y 4) HOUTOUKHSHI, que se dedican a todos los oficios.

Para Widengren? en el antiguo Irán el rey se elegía por el pueblo o, mejor dicho, por la casta guerrera. Este hecho tiene su exponente en el primer libro de Heródoto con el relato de Deyoces ${ }^{8}$. Se trata de la historia de un hombre que juzgaba rectamente en Media; las gentes de esta región pensando que, sin duda, debían ser gobernados por un rey para tener garantía de orden sin estar expuestos a la anarquía, deciden proponer para el cargo al justo Deyoces. Una vez convertido en rey, comienza a organizar el reino. Pide que le construyan una residencia, constituir una guardia personal y erigir una única capital. Además de ello instituye el protocolo a seguir con respecto al rey: «(...) que nadie compareciera ante el rey -ni éste ser visto por nadie - sino utilizar en todo momento los servicios de introductores (...)"; la justificación de estas medidas estribaba en que: «(...) se rodeó de estas formalidades para evitar que las gentes de su misma edad (...) pudieran molestarse y conspirar» ${ }^{9}$.

La persona del rey será sagrada y se le considerará descendiente de los dioses. El acto especial de obediencia, el ceremonial de la corte, la «proskynesis», etc., reflejará su carácter divino. Será también un sacerdote, partícipe principal en el festival del Año Nuevo, de muchas asociaciones simbólicas y cósmicas. El día de la coronación será su cumpleaños, produciéndose al mismo tiempo un "renacimiento", asumiendo un nuevo nombre y nuevos ornamentos que simbolizarían su posición como gobernante cósmico. A su muerte, su «fuego personal» se extingue, y el duelo por parte de su familia y servidores tomarán, en ocasiones, la forma de suicidio o mutilaciones ${ }^{10}$.

\section{RELIGIÓN Y REALEZA}

El concepto de monarquía, característico del Este, estuvo basado en la teoría de que el dios delegaba en un hombre como su representante. En tiempos de paz actuaba como un cargo sacerdotal, pero en tiempo de

\footnotetext{
FRYe, R.N.: La herencia de Persia, Madrid, 1965, pp. 126-129.

Heródoto de Halicarnaso, Historia, I, 97-100.

Idem. Libro III, 99.2.

10 Frye, R.N.: La herencia de Persia, pp. 126-129.
} 
guerra se convertía en un líder militar, que luchaba por él y por su dios. EI poder militar se incrementó usualmente a expensas de la religión y el ritual ${ }^{11}$. El buen desarrollo del reinado dependía del mantenimiento de unas buenas relaciones con el sacerdocio. No obstante, Darío, aunque proclamado rey por derecho divino, no fue un déspota cuyo absolutismo se derivara de su dios nacional ${ }^{12}$, aunque la obediencia al rey y el culto de este dios fueran un mismo deber ${ }^{13}$ y esto fuera motivo para que se empleara el argumento divino para ejercer la voluntad del rey. A pesar de ello no está atestiguado que los primeros aqueménidas se consideraran a sí mismos «hermanos del Sol y la Luna» y por tanto sagrados. Además, parece que para los aqueménidas incluso la «proskynesis» no significaba una humillación servil ante un dios, sino una muestra de respeto ante la realeza.

La coronación tenía lugar en Pasargadas, donde el nuevo rey era iniciado por sacerdotes en el santuario de una diosa, probablemente Anahita, dándosele posteriormente el traje de Ciro. Según la costumbre, no según la ley, el primer hijo nacido después de dicha ceremonia recibía el título de heredero ${ }^{14}$.

Tras la ceremonia de elevación, el rey se convertía en la fuente de poder y del derecho. La ley persa era inmutable e irrevocable excepto cuando se aplicaba a la persona real ${ }^{15}$. A este respecto, escribe Heródoto (III, 31) que queriendo Cambises casarse con una hermana suya, reunió a los jueces reales para preguntarles, pues estos individuos administraban justicia a los persas, siendo intérpretes del derecho consuetudinario. Ellos habían encontrado que según una ley «(...) al rey de los persas le estaba permitido hacer lo que quisiera». El rey será el señor y tendrá el poder por la acción de Ahuramazda como puede apreciarse en una inscripción de Babilonia: "Un gran dios es Ahuramazda, quien creó esta tierra y al hombre (...) quien ha hecho rey a Jerjes».

\footnotetext{
11 Heródoto escribe que «Tras la toma de Babilonia, tuvo lugar la expedición que el mismísimo Darío acaudilló contra los escitas», Libro IV.1.

12 Dicks, B.: The ancient Persians. How thev lived and worked, Devon, 1979.

13 BENVISTE, E.: “L'Iran antique: les achemenides", pp. 44-47 en La civilisation iranienne, Paris, 1952.

14 Artobázanes (...) reclamaba (el trono) pues era el primogénito y (...) era una costumbre admitida por todo el mundo que el primogénito llegara a ejercer el poder", Libro VII.2-3. Por otra parte, en VII.3.3 escribe que Demarato expresa a Jerjes una opinión en el mismo sentido: (...) si el monarca tiene hijos habidos antes de su ascensión al trono, y, una vez entronizado, tiene otro, recae en éste la sucesión (...)".

15 Olmstead, A.T.: History of the Persian empire, Chicago, 1978, pág. 231.
} 
En Behistum, una inscripción que relata los acontecimientos del final del reinado de Cambises y los primeros del de Darío I, puede verse a éste, con dos de sus seguidores, pisando, con el arco en la mano, la cabeza de Bardiya - Gaugamata-, mientras que tras éste esperan encadenados su juicio implacable los otros rebeldes y los "reyes falsos". Sobre ellos vuela Ahuramazda en el disco solar alado, ofreciendo al rey el anillo del poder. Esto es algo que se corresponde con los ideales del antiguo oriente. La inscripción en persa, babilónico y elamita, da pruebas de un espíritu basado en cierta responsabilidad ética ante la divinidad ${ }^{16}$ (figura 3).

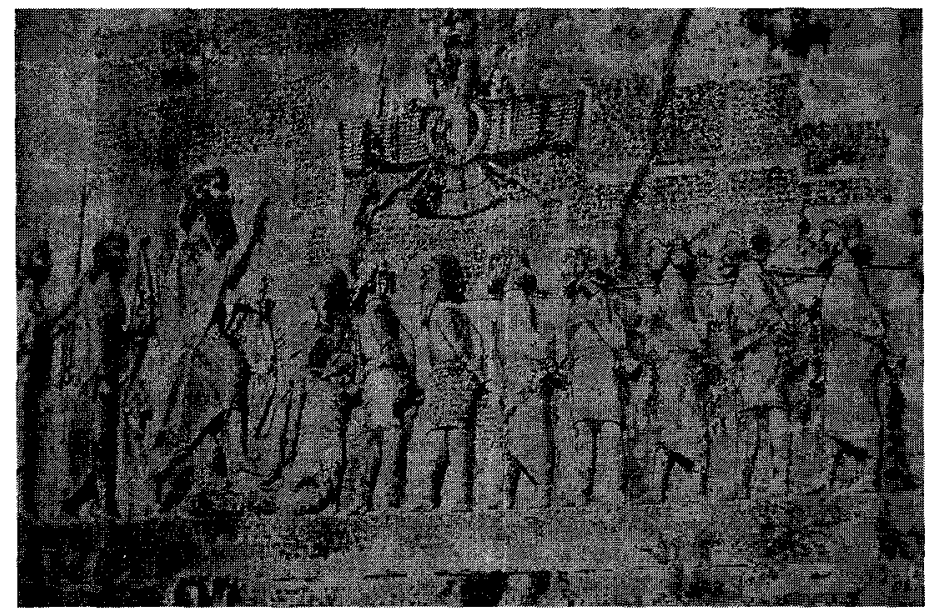

Figura 3. Relieve de Behistum. Esta especie de «manifiesto de constitución", narra las hazañas de Darío l y la organización del Imperio.

\section{RELIGIÓN, REALEZA E IMPERIO}

La inscripción anteriormente reseñada de Behistum, relata las hazañas del rey y la organización del imperio. En este momento de finales del siglo vi a.C., Persia estaba consolidándose bajo el primer soberano de la nueva dinastía proveniente de una rama colateral de la dinastía aqueménida. Darío, en sus enfrentamientos por consolidar el poder estuvo sostenido por la fuerza espiritual de las enseñanzas de Zoroastro. Con ello, él representaba el reino en nombre de la verdad, de la justicia y del bien del

16 Von Der Osten, H.H.: El mundo de los persas, Madrid, 1965, pág. 71. 
género humano; por contraposición, sus enemigos eran las fuerzas del mal que conspiraban para la ruina del mundo. Era evidente que las razones de carácter político convergían con las económicas y con los motivos religiosos en el momento de realizar la conquista total del mundo mediterráneo de modo que las fuerzas del mal pudieran ser erradicadas ${ }^{17}$.

La monarquía universal era una idea ya antigua a la que la religión de Zoroastro había dado un nuevo carácter, puesto que la unificación de todos los pueblos bajo el cetro de un rey que fuera un fiel defensor de los principios religiosos del mazdeismo, equivalía a la expulsión del mal de todos los lugares que obstaculizaban la expansión y el dominio de Persia.

Económicamente, la monarquía persa tenía en común con todos los poderes políticos autoritarios la prevención contra los cambios que se producian en otra frontera, disminuyendo su propio poder y la independencia de la organización. No veía con buenos ojos el que parte de su riqueza fuera a parar al exterior de sus fronteras y que la industria y la actividad económica estuviera a merced de las importaciones de materias primas. Por otro lado, existía un factor psicológico centrado en el prestigio del rey desde el punto de vista político y militar. El rey debía conseguir una reputación como vencedor y conquistador de pueblos ${ }^{18}$ (figura 4).

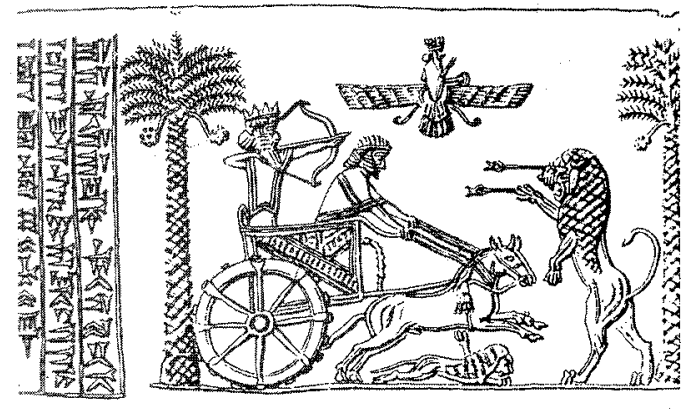

Figura 4. Impresión de un cilindro-sello con el nombre de Darío quien es representado en una escena cinegética para manifestar su poder.

17 LEVI, M.A.: Storia universale dei popolo e delle civiltà, IIl, «Grecia e Persia», Torino, 1970, pp. 41-42.

18 El rey Jerjes habiendo reunido a los principales del país les dice: «(...) he estado meditando el medio para no desmerecer de mis predecesores en este cargo y para anexionar al imperio persa no menos territorios». Jerjes había decidido invadir Grecia. Historia VII, 8.2. 
Ideológicamente, el espíritu que alentaba la nueva cultura griega era inaceptable para los persas, en cuanto que contravenía los principios más importantes del mazdeismo, sobre todo después de la reforma de Zoroastro. Aunque éste habla predicado una nueva valoración de la personalidad humana y había combatido el concepto que negaba toda dignidad al hombre, a su mente y a su trabajo, para Zoroastro la dignidad humana consistía en dedicarse totalmente al servicio de la divinidad y en trabajar y combatir para el triunfo de su voluntad. De esta forma, aquélla intervendría en todos los actos de la vida humana. La monarquía persa hubiera perdido su razón de ser si no se hubiera aceptado esta concepción. Todo ello chocaba, a su vez, con la idea griega de la absoluta independencia del hombre de la guía e intervención sobrenaturales ${ }^{19} \mathrm{y}$ del sometimiento al imperio de la ley ${ }^{20}$. Se marcaban aquí, claramente, las diferencias entre los regímenes políticos y su organización. Interesante, en este punto, es la transmisión que Heródoto hace de la discusión en torno al mejor régimen de gobierno ${ }^{21}$ y la elección de la monarquía.

Muertos los magos que gobernaban Persia, los siete conjurados discutieron sobre la mejor forma de organizar el Estado. Otanes solicitaba que la dirección del mismo se pusiera en manos de todos los persas conjuntamente, puesto que con una monarquía, al rey le estaría permitido hacer todo lo que quisiera y, dado que la prosperidad engendra la soberbia, «(...) ahito como está de todo (el rey), comete numerosos e insensatos desafueros (...) ${ }^{22}$. Sigue argumentando Otanes sobre las ventajas de que las magistraturas se desempeñen por sorteo, rindiendo cada uno cuentas de su cargo y sometiendo todas las deliberaciones a la comunidad. Otro de los conjurados, Megabizo, quería que se confiara el poder a una oligarquía, pues «(...) no hay nada más necio e insolente que una muchedumbre inepta (...), elijamos, pues, a un grupo de personas de la mejor valía y otorguémosle el poder" ${ }^{23}$. Le llegó, al fin, el turno de hablar a Darío, quien realiza ante los conjurados una sólida defensa de la monarquía. Comienza su parlamento diciendo que no hay nada mejor que un único gobernante,

\footnotetext{
${ }^{19}$ Op. cit., n. ${ }^{\circ} 17$, pág. 57.

${ }^{20}$ Demarato al dirigirse a Jerjes le dice: «(...) pese a ser libres, no son tan fibres del todo, ya que rige sus destinos un supremo dueño, la ley, a la que, en su fuero interno, temen mucho más de lo que tus súbditos te temen a ti». Historia VII, 104.4-5.

21 Historia III.80-88.

22 Historia Ill.80-4.

23 Historia III.81.
} 
si éste es un hombre de valía, puesto que cuando gobiernan varios como en la oligarquía, acaban apareciendo disensiones entre sus integrantes. Cuando, por otra parte, es el pueblo quien gobierna, no existe medio para evitar que brote el libertinaje. Ambas formas tienen como conclusión final e inevitable la monarquía. Darío, concluye proporcionando el argumento definitivo al referirse a Ciro, mediante el cual consiguieron la libertad. El resto de los conjurados acepta finalmente la monarquía y Darío queda proclamado rey mediante una selección que se deja al azar del destino y a la elección de los dioses. Después de ello «(...) todos los pueblos de Asia, salvo los árabes, fueron súbditos suyos (...)».

Darío fue coronado en Pasargada. Casi inmediatamente llevará a cabo una reorganización del imperio ${ }^{24}$, cuyo fundamento principal estribaba en la relación personal de lealtad establecida entre el "Gran Rey" con sus súbditos, quienes se sienten obligados hacia él por medio de una obediencia incondicional. La reforma del imperio tomó un cariz admínistrativofinanciero, la cual facilitó la creación de un sistema estable de administración y control sobre los pueblos conquistados en orden a la recogida de impuestos y a incrementar los contingentes de tropas.

El imperio aqueménida se distinguía en términos socio-económicos por su enorme diversidad, al englobar regiones de Asia Menor, Elam, Babilonia, Siria, Fenicia o Egipto. Por ello, se encontraron muchas dificultades para crear un sistema unificado de administración, aunque tampoco los monarcas anteriores habian realizado muchos esfuerzos para cambiar un sistema imperial que no alterara las estructuras locales y la tradición regional. El imperio permaneció como una unión militar y administrativa en el que cada provincia se estableció como una región socio-económica independiente con sus propias instituciones económicas, sus leyes locales, costumbres, sistemas monetarios... A pesar de ello fueron produciéndose diversos cambios en la estructura de la administración.

Darío dividió el estado en distritos administrativos de carácter impositivo, llamados satrapías. En palabras de Heródoto: (...) «una vez hecho esto, implantó en el imperio persa veinte provincias (...)». Sus dimensiones eran mayores que las de las provincias de los antiguos imperios y las fronteras coincidían con las fronteras políticas y etnográficas de los pueblos

24 Bengtson, H.: Griegos y persas, Madrid, 1975; puede también verse DandanaeV, M.A. y LUKONIN, V.E.: The culture and social institutions of Ancient Iran, Cambridge, 1968, pp. 96-116 y Heródoto, Historia ill. 89 y ss. 
que habian sido parte del imperio aqueménida. La división era económica, continúa Heródoto: «(...) después (...) determinó los tributos que debían llegar a sus manos según los diferentes pueblos, incluyendo en la circunscripción de éstos a sus vecinos y distribuyendo en varios los pueblos más lejanos». Reorganiza el sistema monetario, creando el «dárico», moneda de oro con la efigie del rey blandiendo un arco ${ }^{25}$. Sigue relatando Heródoto que «(...) fijó las provincias y la aportación anual de tributos de la siguiente manera: a los pueblos que satisfacían su tributo en plata se les dio orden de satisfacerlo con arreglo al peso del talento babilonio, y con arreglo al del euboico a los que lo satisfacían en oro».

Heródoto proporciona la lista de las satrapías, pero sólo corresponde parcialmente a la lista de la inscripción de Behistum y a otras referencias halladas en Naqsh-i-Rustam, Persépolis y Susa. En estas inscripciones, a las divisiones territoriales se les llama «países». Según la primera de las inscripciones estas divisiones eran las siguientes:

1) Persia, 2) Huza, 3) Babairu, 4) Athura, 5) Arabaya, 6) Mudraya (Egipto), 7) La llamada “Satrapía del borde del mar», 8) Sardes, 9) Yauna, 10) Mada, 11) Armina, 12) Capadocia, 13) Partia, 14) Zranka, 15) Haraiwa, 16) Huwarazmiya, 17) Bactria, 18) Sogdiana, 19) Gandhara, 20) Saka, 21) Tatagus, 22) Harahuwati y 23) Maka. Más tarde se añadirán otras como Putiya (Libia), Kusiya (Nubia) y Skudra (Tracia) ${ }^{26}$.

Para Heródoto ${ }^{27}$, ya hemos dicho que las provincias eran veinte, según sus palabras: «(...) jonios, magnesios de Asia, eolios, carios, licios, milios y panfilios formaban la primera provincia (...)", de esta manera sigue enfimerándolas hasta completar dicho número, utilizando este criterio etnográfico: 2) Pueblos del Helesponto, frigios, tracios de Asia, paflagones, morrandinos y sirios, 3) Misios, lidios, lasonios, caballos e hitineos, 4) Cilicios, 5) Fenicia, Siria que se llama Palestina y Chipre, 6) Egipto, libios a orillas del río, Cirene y Barca, 7) Satágidas, gondonios, dedicas y los aparitas, 8) Babilonia. 9) Resto de Asiria, 10) Ecbatana y resto de Media, país de los paricanios y los doritas, 11) Caspios, pausicas, pantimatos, doritas, 12) Abarca desde el país de los bactrianos hasta el de los eglos, 13) de Páctica, de los armenios y de los pueblos limítrofes, hasta el Ponto Euxino, 14) Sagartios, soranjas,

\footnotetext{
25 «(. .) Darío mandó refinar oro en el mayor grado de pureza posible y con él acuñó moneda", Historia IV.166.

26 Bengtson, H.: op. cit., n. 24.

27 Historia HI.90-97.
} 
tamaneos, utios, micos y los habitantes de las islas del mar Eritreo, 15) Sacas y caspios, 16) Partos, corasmios, sagdos y arios, 17) Paricanios y etíopes de Asia, 18) Matienos, saspires y alarodios, 19) Moscos, tibarenos, macrones, mosinecos y mares y 20 ) Indios. Las divergencias en la enumeración de las satrapías estriban en que en las inscripciones de Naqsh-iRustam se aporta la lista de los distritos administrativos, mientras que en Heródoto aparece la lista de las regiones sometidas (figuras 5 y 6 ).

Por lo que se refiere a los tributos que debían satisfacer dichas provincias, Heródoto da cuenta de que «(...) los persas habitan un territorio que goza de exención de impuestos. Por otro lado, habla pueblos que no habían recibido orden de satisfacer tributo alguno, pero que entregaban presentes"; entre estos últimos se encontraban los etíopes, los colcos y los árabes ${ }^{28}$. Los tributos confluían en tesoros centrales emplazados en las residencias reales. En Persépolis se ha encontrado la casa-tesoro (ganzaka) y un gran número de tablillas de arcilla escritas en lengua elamita con liquidaciones de cuentas, como Cameron y Hallock han mostrado.

Los sátrapas ${ }^{29}$ estaban al frente de la nueva administración. De acuerdo con Heródoto ${ }^{30}$ parece que fue introducido por Darío, no obstante, proviene del persa «Khshtrapavan» o "protector del reino» —en los párrafos 38 y 35 de la inscripción de Behistum- y es muy probable que apareciera por vez primera en una lista de Sargón sobre los caudillos medos, como Grantovsky ha demostrado. El título designaría, incluso anteriormente a la emergencia de Media, a los jefes independientes del NW de Irán.

Darío limitó la autoridad del sátrapa, habiendo establecido una tajante división entre las funciones de estos gobernadores y las autoridades militares. Ahora los sátrapas se volvieron meros gobernadores de carácter civil, a la cabeza de la administración de su región, ejerciendo la autoridad judicial, rigiendo la vida económica, los impuestos (Historia L.42), la seguridad de las fronteras, la supervisión de los funcionarios locales, además de poseer el derecho a acuñar moneda. En épocas de paz sólo tenía una pequeña guardia ${ }^{31}$; estaba, no obstante, bajo la autoridad de los jefes mi-

Historia III.97.

29 Heródoto nunca menciona la palabra sátrapa, puesto que será Jenofonte quien por vez primera la utilice. En ese caso podría ser traducida por el equivalente a gobernador como en III.120 «Era gobernador de Sardes (...)» o en VI.42 «Artafrenes, el gobernador de Sardes (...)».

30 Historia III.89.

31 Historia III.128. 


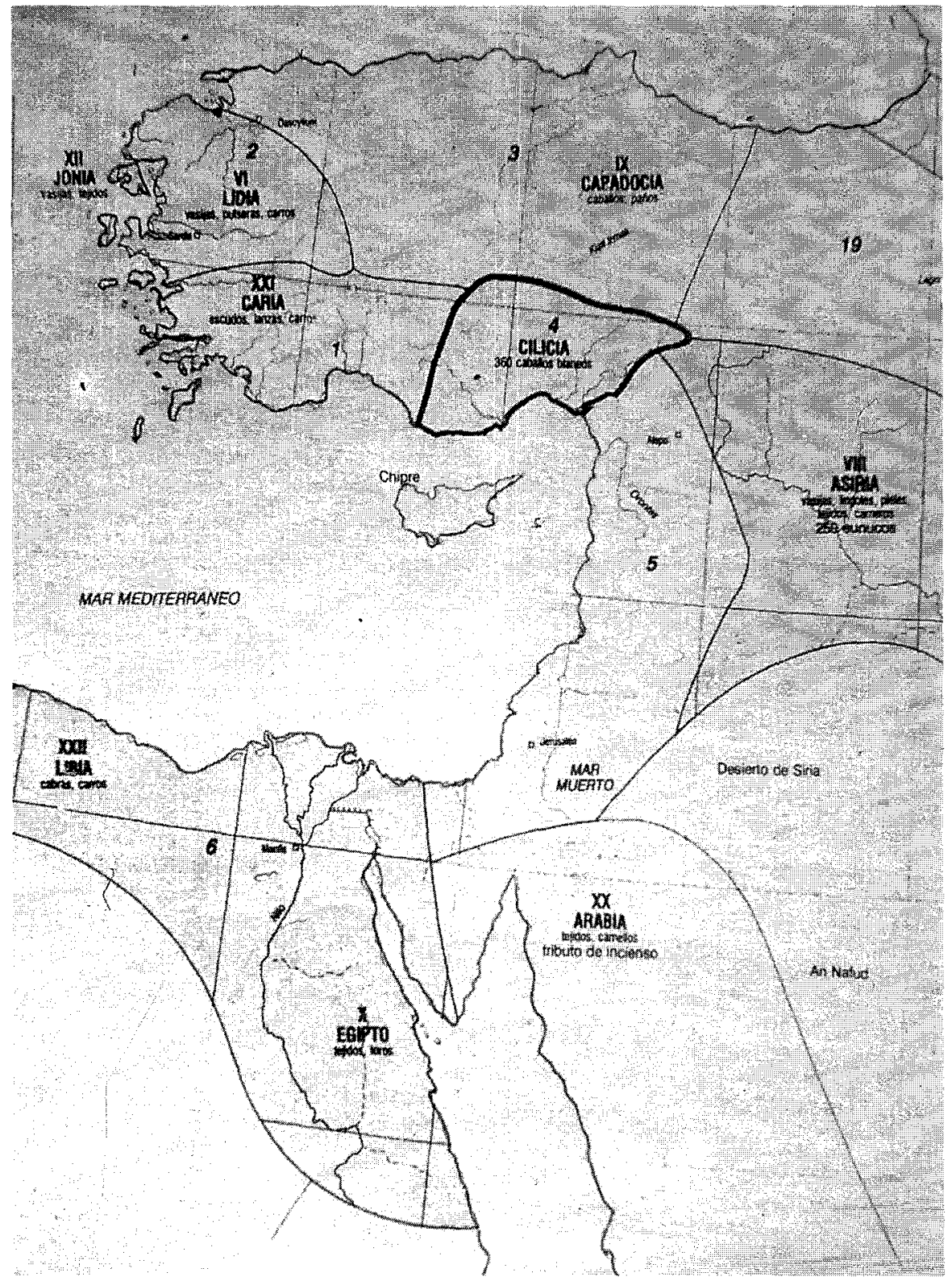

Figura 5. Mapa que muestra la división del imperio en satrapias, según las inscripciones persas y Heródoto. (Mapa procedente de M. Roaf, Mesopotamia y el antiguo oriente medio, Madrid, 1988. Ed. Folio.) 


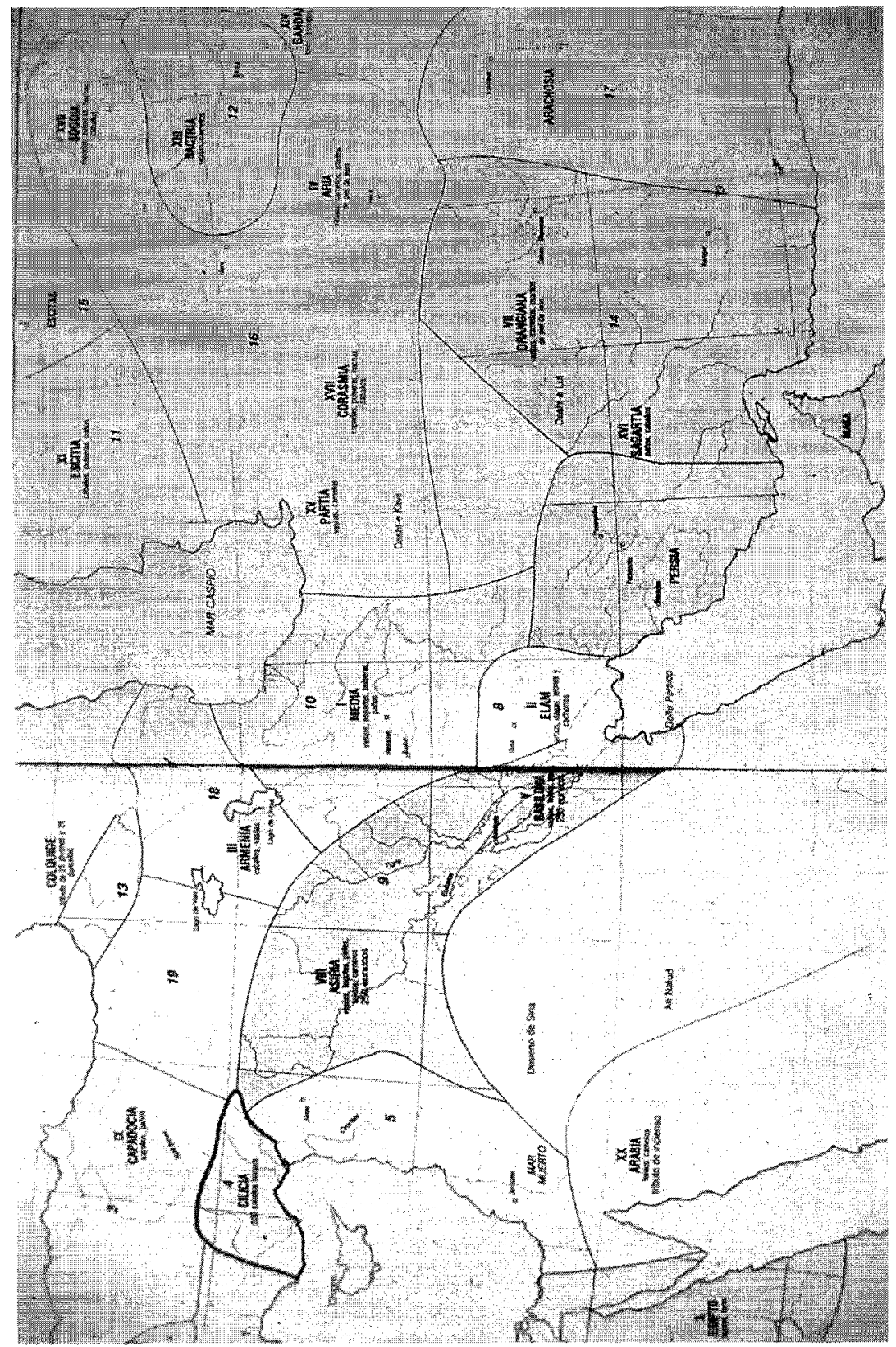


litares que eran independientes de los sátrapas y subordinados directamente al rey.

Tras la muerte de Darío, sin embargo, la división anterior en funciones civiles u militares no fue tan estrictamente observada. Con Jerjes y otros gobernantes posteriores, algunos sátrapas dependerán también de caudillos militares, pero no serán raros aquéllos que ejercerán la autoridad cívico-militar. Puede verse este hecho en el relato que Heródoto hace de las campañas de Jerjes contra Grecia. En ocasiones, a partir de este momento, dos o tres satrapias estuvieron en manos de un sólo hombre. Aparentemente, tanto antes como después de las reformas de Darío el plazo de gobierno de una satrapía no estaba limitado por el tiempo, así a Zopyros, Darío le otorga el gobierno de Babilonia de por vida. En otras ocasiones tenemos muestras de sucesiones hereditarias en el gobierno como el caso del persa Artabazos (figura 7).

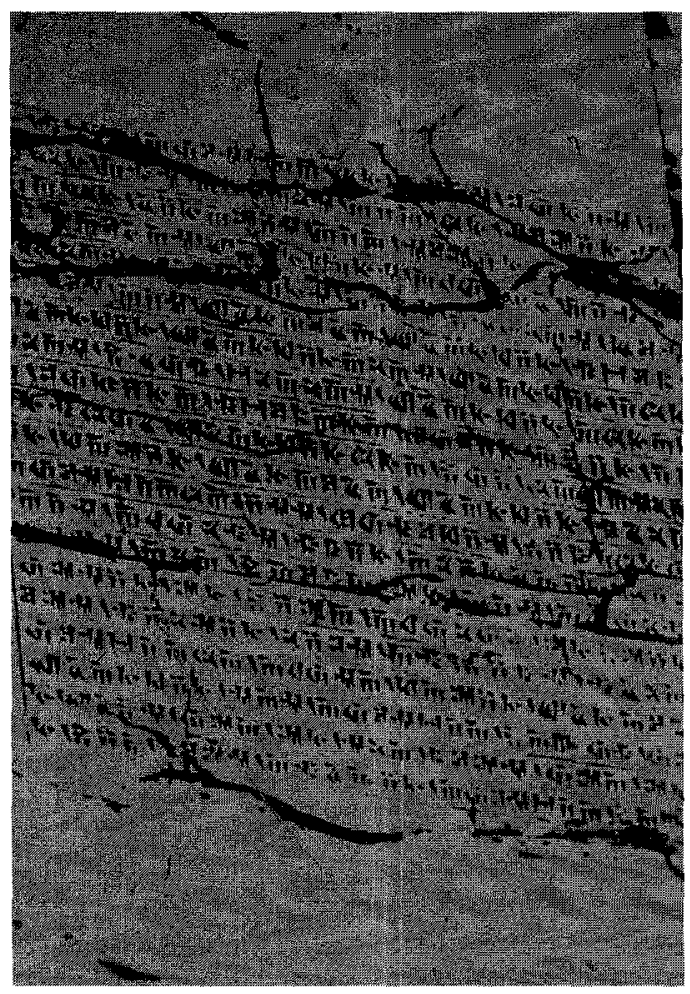

Figura 7. Versión persa antigua de una inscripción de Jerjes, procedente de Persépolis. 
El título de sátrapa ${ }^{32}$ no fue usado sólo por los gobernadores de los más grandes distritos administrativos, sino también por jefes de pequeñas regiones que formaban parte de la satrapía, aunque estuvieran subordinados a sus propios gobernadores. Estas pequeñas divisiones coincidian, algunas veces, con antiguas divisiones como la de los nomos en Egipto. Las ciudades o paises con autonomía en los asuntos internos estaban incluidos en las más extensas, sobre todo en las más lejanas y remotas, en las que Persia apenas intervenla. Tenemos el ejemplo de la inexistencia de sátrapas en Chipre o Cilicia, pero también Paflagonia, Licia, etc., donde tenían sus propios gobernantes, incluso con el derecho de transmisión hereditaria del poder. Tribus remotas como las de los árabes o etiopes estaban gobernados por sus propios jefes tribales. Por lo que se refería Persia misma, no está claro qué parte administraba el sátrapa y cuál estaba bajo la dirección directa del rey. Según Heródoto ${ }^{33}$ el padre de Darío, Histapes, fue gobernador de Persia. Sin embargo, la inscripción de Behistum establece que Histapes fue un sátrapa de Partia e Hircania, no de Persia. Es posible que el rey concediera el gobierno de parte del territorio a sus hijos, como se dice en los comienzos del libro III ${ }^{34}$. También, el heredero al trono era nombrado virrey de una de las satrapías importantes: Babilonia. Sin embargo, el sucesor debía estar preparado para las tareas de gobierno puesto que, según escribe Heródoto, "mientras Darío se aprestaba a dirigirse contra Egipto y Atenas, se suscitó entre sus hijos un serio altercado a propósito del trono, pues de acuerdo - decian-con la norma vigente entre los persas, para poder entrar en campaña, el monarca debía designar un sucesor» ${ }^{35}$, con ello este posible sucesor podía haber desempeñado con anterioridad las funciones de gobernador de Persia.

Por lo que se refiere al funcionamiento del propio imperio, fue creado un aparato central encabezado por el canciller real. La administración se localizaba en Susa. Esta importante capital se hallaba localizada en el centro territorial, bien comunicada por un canal con el Golfo Pérsico y por distintas vías con Ecbatana, Babilonia y Persépolis. Las órdenes salían de Susa a todas las provincias, mientras los informes de los sátrapas y

32 Sobre la organización de las satrapías BURN, A.R: Persia and the greeks, London, 1984.

33 Historia III.15.2 «(...) los persas tienen por costumbre conceder honores a los hijos de los reyes; $y$, aunque estos últimos se subleven contra ellos, a pesar de todo devuelven el poder a sus hijos".

34 Historia III.70.

35 Historia III.2. 
otros funcionarios iban destinados al rey. Aquí entraban a ejercer su papel los «introductores de mensajes" y los eunucos ${ }^{36}$, ejerciendo los primeros una suerte de funciones protocolarias con todos aquéllos que querían ver al rey. Grandes personajes y pequeños funcionarios llegaban a Susa desde todos los confines del imperio como Egipto o La India, una multitud de funcionarios y escribas se encargaban de la correspondencia oficial y de las peticiones, no solamente en Susa sino en Babilonia, Ecbatana, Menfis y otras ciudades.

Un servicio postal regular fue puesto a trabajar para la administración de las provincias. Estaciones con posadas, situadas a distancias de un día de camino y custodiadas por el estado, existían en las grandes vías de comunicación. Escribe Heródoto ${ }^{37}$ que «(...) ningún mortal hay que se presente más rápidamente que estos mensajeros (...) pues dicen que de cuantos días (sea) todo el recorrido, tantos caballos han sido puestos de trecho en trecho, puesto un caballo y un hombre por cada recorrido diario (...) El primer corredor, pues, entrega el encargo al segundo y el segundo al tercero (...)" Diversas fortificaciones fueron emplazadas a lo largo de los más importantes pasos. De esta forma, se localizaban 111 estaciones en el camino de Sardes a Susa ${ }^{38}$. Continúa su relato apostillando que todas las carreteras del imperio estaban guardadas por patrullas que controlaban a los viajeros ${ }^{39}$.

La necesidad de buenas comunicaciones venía dada por las propias necesidades de la corte y el movimiento constante que ésta efectuaba a lo largo del año, debiendo estar en contacto permanente con los centros administrativos y de poder. La corte real se encontraba en otoño e invierno en Babilonia, en verano en Ecbatana y en la primavera en Susa, aunque el tiempo de las grandes vacaciones se pasaba en Pasargadas y Persépolis, siendo en la primera donde se producian la coronación y elevación al trono, por lo cual gozaba de una cierta primacía (figura 8).

El aparato central de gobierno se organizó de acuerdo al modelo babilonio, cuyos métodos y procedimientos se difundieron a lo largo de todo el imperio. Los sátrapas y los jefes militares estaban vinculados estrechamente con la administración central y con el constante control del rey y sus

36 Historia VIII.2.

37 Historia VIII.98.

38 Historia V.53.

39 Historia V.52 «(. .) la totalidad de la ruta discurre por regiones habitadas y seguras ( )». 


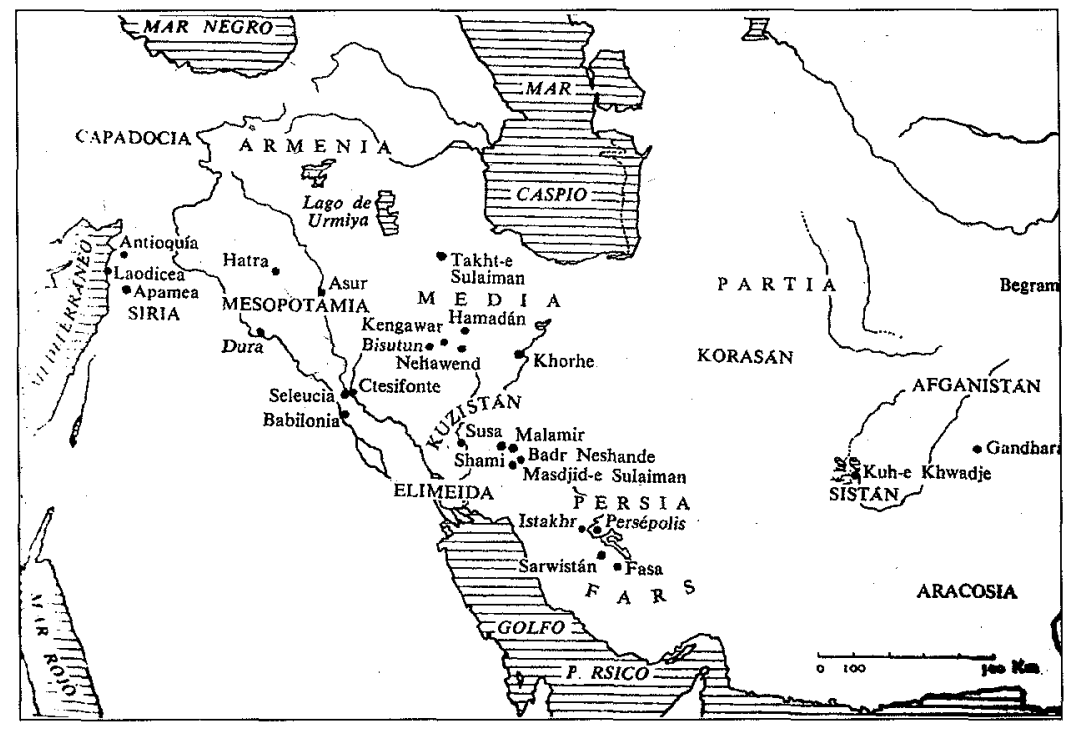

Figura 8. Localización de los principales asentamientos persas.

funcionarios. Esta supervisión se realizaba a través de los denominados “ojos" y "oídos» del rey, quienes eran independientes de los sátrapas y de otras autoridades locales. Estaban subordinados directamente al rey y le informaban de toda palabra o acto sedicioso que pudiera producirse. El secretario asignado al sátrapa era también independiente y estaba considerado como un escriba real. Era el lazo de unión entre el gobierno central y la cancillería de la región en cuestión ${ }^{40}$. Según Jenofonte, también el gobernador de la región y el jefe militar frecuentemente informaban al rey. Cuando éste se encontraba de viaje, las funciones de policía estaban desempeñadas por los «portadores de alfombras" reales, encargados tanto de la comodidad de los reyes como de despejar el camino de los elementos indeseables. El rey aparte de estos informadores se rodeaba también de consejeros de su elección; así Darío le dice a Histieo «(...) tuyo será todo lo que poseo, y además compartirás mi mesa y serás mi consejero» ${ }^{41}$.

El supremo control del estado entero y los funcionarios, estaba en manos del llamado "Jefe de los diez mil». Era simultáneamente jefe de la guardia 
personal del rey (de los primeros mil de los «inmortales») y jefe de la cancillería central del estado. El también informaba al rey acerca de los visitantes y los introducía ante de él. Nepote escribe que el «jefe de los mil» ocupaba la segunda posición después del rey en el estado y nadie era admitido en presencia del mismo sin su consentimiento. En casos de necesidad, el rey enviaba inspectores especiales para investigar los hechos en las provincias.

La cancillería del sátrapa estaba organizada exactamente igual que la cancillería real en Susa. Un gran número de funcionarios se hallaba bajo el mando del sátrapa, incluyendo el jefe de la cancillería, el encargado de las instrucciones oficiales, el director de la casa del tesoro, el recaudador de los impuestos, los heraldos que públicamente proclamaban las órdenes oficiales, contables, investigadores judiciales y numerosos escribas. Tal sistema de cancillería fue también característico de pequeñas regiones, ciudades, etc.

Los persas ocuparon una posición especial y de privilegio en todo este entramado administrativo. Los más importantes puestos civiles y militares, no sólo en Persia misma sino también en otras ciudades, se concentraban en sus manos. Después de las reformas de Darío, los persas aparecen incluso en las oficinas provinciales de Babilonia y otras ciudades como jueces. Sin embargo, se emplearon también a gentes de los países conquistados. De esta forma, jueces, directores de cancillería, recaudadores de impuestos, monarcas, etc., fueron babilonios, asirios, arameos, elamitas, incluso los extranjeros a veces alcanzaron altos puestos.

Todo ello, pese a la multiplicidad de pueblos, contribuyó a hacer del imperio persa un cuerpo unificado, una estructura estable y duradera y un modo de consagrar y consolidar el poder del rey como cabeza de todo este entramado. Como ya expresábamos anteriormente, durante las guerras médicas entraron en confrontación este modelo y el griego, de carácter completamente diferente. Grecia, a pesar de la expansión comercial que habla provocado la fundación de numerosas colonias, no formó ningún imperio, aunque Heródoto ${ }^{42}$ encuentre algunas similitudes. Estos asentamientos deberán bastarse a si mismos y siempre les faltará cohesión. Las "polis" no se relacionarán unas con otras y ni siquiera existirá una gran idea común, ni un sentimiento nacional helénico que sólo incipientemente

42 Historia VI.59 "Los espartanos coinciden con los persas en esta otra particularidad: cuando, a la muerte del rey, otro monarca, asume el poder, el nuevo soberano condona a todos los espartiatas sus deudas con el rey o el Estado. Entre los persas, el rey que accede al trono exime a todas las ciudades del tributo que aún no hayan satisfecho». 
se formará al comienzo de las hostilidades con los persas. No era bastante el reunirse en competiciones atléticas, tener unos antepasados míticos comunes o un sustrato espiritual vinculante a todos los griegos. Todo ello hacia de Grecia una entidad invertebrada y dominada por un individualismo casi inexistente en Oriente y a través del que se gestará la genialidad de las aportaciones del mundo griego a la cultura política universal. La obra de Heródoto, como parte de la misma, situará al hombre en el centro de los pueblos y los paises, describiendo en última instancia la gran lucha producida entre el Oriente y el Occidente ${ }^{43}$.

\section{BIBLIOGRAFÍA}

BEngtson, H.: Griegos y persas, Madrid, 1975.

BENVISTE, E.: "L'Iran antique: les achemenides" en La civilisation iranienne, París, 1952.

BRANAN, P.T.: "Herodotus and history. The constitutional debate preceding Darius accesion", en Traditio 19 (1963), pp. 427-438.

Brun, A.R.: Persia and the Greeks, London, 1984.

CAMERON, G.G.: «Persepolis treasury tablets old and news», J.N.E.S. 17 (1958), pp.161-76.

Cullcan, W.: Medos e Persas, Lisboa, 1971.

DANDANAEV, M.A., y LUKONIN, V.E.: The culture and social institutions of ancient Iran, Cambridge, 1968.

De SANCtIS, G.: "La composizione della storia di Erodoto», en Rivista di Filologia e di Istruzione classica, 4 (1926), pp. 289-310.

Dicks, B.: The ancients persians. How they lived and worked, Devon, 1979.

DUMEZIL, G.: «Les classes sociales dans la Perse ancienne», en La civilisation iranienne, París, 1952.

FRYE, R.N.: La herencia de Persia, Madrid, 1965.

GHanl, C.: Iran and the West. A critical bibliography, London, 1987.

GHRISMAN, T.: L'Iran des origines a l'Islam, París, 1951.

GREENFIELD, J.C. y PORTER, B.: The Bisitum inscription of Darius the Great (aramaic version), ClI, Part 1, Vol. 5, 1982.

Hallock, R.T.: Persepolis fortification tablets, Chicago, 1969.

HARMATA, J.: "The Bisitun Inscription and the Introduction of the old Persian cuneiform script", AA 14 (1966), pp. 255-283.

HELM, P.R.: "Herodotus Mêdikos Logos and Median History», Iran, 19 (1981), pp. 85-90.

HeRzFELD, E.: The persian empire, Wiesbaden, 1968.

Huot, J.L.: Iran. Des origines aux achemenides, I, Geneve, 1965.

JaEger, W.: Paideia: los ideales de la cultura griega, México, 1957.

KENT, R.G.: «The list of Provinces", JNES, 2 (1943), pp. 302-306.

LEVI, M.A.: "Grecia e Persia", en Storia universale dei popolo e dei civiltà, III, Torino, 1970.

MOUSNIER, R.: Monarchies et royautés, París, 1989.

OLMSTEAD, A.T.: History of the persian empire, Chicago, 1978.

OLMSTEAD, A.T.: "Darius and his Behistun Inscription", American Journal of Semitic Languages and Literatures, 55 (1938), pp. 392-416.

PLÁCIDO, D.: «La teoría de la realeza y las realidades históricas del siglo IV a.C.» en La imagen de la realeza en la Antigüedad, Madrid, 1988.

43 JaEger, W.: Paideia: los ideales de la cultura griega, México, 1957, pág. 345. 
POPE, A.U.: «Persepolis as a ritual city», Archaeology, 10 (1957), pp. 123-130.

REgourd, F.: “Le role de l'élite persa dans la formation de l'armée et de l'etat Achéménides», Acta Iranica, 2 (1974), pp. 100-107.

TILLIA, A.B.: Studies and restorations at Persepolis and other cities of Fars, Rome, 1972.

TOLMAN, H.C.: "The Persian Basiliéioi theoi of Herodotus III, 65, V, 106", TPA, 33, Ixxvii-Ixx.

TREIDLER, H.: «Pasargadae», PW, 9 (1962), pp. 777-779.

TRICHET, J.: «Etude pétrographique de la roche constituant la statue de Darius découverte a Suse en décembre 1972», DAFI, 4 (1974), pp. 57-9.

TUPLIN, Chr.: "The administration of the Achaemenid Empire», Coinage and administration in the Athenian and Persian Empires (I. Carradice, ed.), Oxford, 1987, pp. 109-166.

VALLAT, F.: «Tabla élamite de Darius I», RA, 64 (1970), pp. 149-60

- «Deux inscriptions élamites de Darius I», Studia Iranica, 1 (1972), pp 3-13

— «epigraphie Achéménide», DAFI, 2 (1972), pp. 203-217.

— «'inscription trilingue de Xerxes a la porte de Darius», DAFI, 4 (1974), pp. $171-80$.

- "La triple inscription cunéiforme de la statue de Darius I (DSab)", Revue d'Assiriologie, 68 (1974), pp. 157-166.

VALLET, F.: «Deux nouvelles "chartes de fondation d'un palais de Darius l», Syria, 48 (1971), pp. 53-9.

WELLS, J.: «The Persian Friens of Herodutus», JHS, 27 (1907), pp. 37-47

WIDENGREN, H.: «The sacred kingship of Iran», en Numen, 4 (1959), pp. 242 y ss.

TEXTO

Heródoto, Historia (int. de F. Rodríguez Adrados), Madrid, 1977. 